\title{
AULAS PRÁTICAS: SUA IMPORTÂNCIA E EFICÁCIA NO ENSINO DE BIOLOGIA
}

\author{
Angélica Tomazeli da Silva ${ }^{1}$ \\ Annie da Silva Cassamali ${ }^{2}$ \\ Leidiane Bino de Castro ${ }^{3}$ \\ Quezia Pains Dutra ${ }^{4}$ \\ Lorayne Stinguel ${ }^{5}$ \\ Elias Terra Werner 6
}

Resumo: O objetivo deste trabalho foi verificar a importância e a eficácia das aulas práticas na aprendizagem significativa dos alunos do ensino médio. Para isto, foram aplicadas aulas com o conteúdo carboidratos para quatro turmas de $1^{a}$ série do ensino médio de uma escola pública estadual, localizada no município de Alegre-ES. Na turma I foi aplicado somente aula prática, na II aula teórica, na III prática + teórica, necessariamente nesta ordem, e por último, na turma IV aplicado teórica + prática, respectivamente, sendo que ao final das aulas aplicou-se uma avaliação com o objetivo de verificar a aprendizagem dos alunos. Os pontos discutidos em ambas as aulas foram os mesmos, e participaram da pesquisa 106 alunos ao todo. A partir dos resultados obtidos observamos que a turma em que foi ministrado a aula prática apresentou um maior rendimento na avaliação, quando comparada aos outros métodos utilizados. $A$ aula teórica foi a que apresentou os menores valores para a avaliação aplicada. As associações destas aulas não tiveram diferença significativa na ordem de aplicação. Portanto as aulas práticas apresentam maior eficácia no ensino deste conteúdo.

Palavras-chave: Ensino médio; Atividades práticas; Carboidratos; Laboratório; Experimento.

\footnotetext{
${ }^{1}$ Ciências Biológicas/Universidade Federal do Espírito Santo, Brasil. E-mail: angelicatomazeli.bio.2012@gmail.com.

2 Ciências Biológicas/Universidade Federal do Espírito Santo, Brasil. E-mail: anniecassamali@hotmail.com.

${ }^{3}$ Ciências Biológicas/Universidade Federal do Espírito Santo, Brasil. E-mail: leidibc@gmail.com.

${ }^{4}$ Ciências Biológicas/Universidade Federal do Espírito Santo, Brasil. E-mail: quezia_dutra@hotmail.com.

${ }^{5}$ Ciências Biológicas/Universidade Federal do Espírito Santo, Brasil. E-mail: lostinguel@hotmail.com.

${ }^{6}$ Departamento de Biologia/Universidade Federal do Espírito Santo, Brasil. E-mail: eliaswerner12@gmail.com.
} 